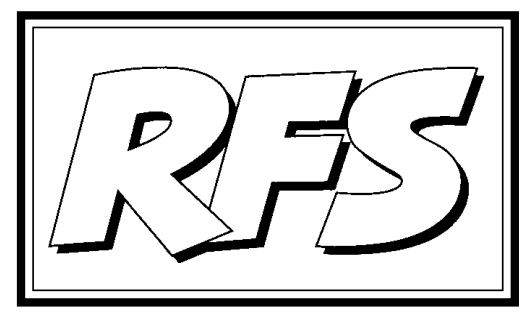

Revista de Fomento Social, 56 (2001), 287-296

\title{
Algunos puntos críticos de la salud laboral y del marco jurídico preventivo
}

Francisco ALEMÁN PÁEZ ${ }^{1}$

\section{Introducción}

La siniestralidad laboral y la labor preventiva son aspectos de una misma problemática que suscita numerosas incógnitas y paradojas. Lo es así, ante todo, por incidir sobre un objeto de protección muy singular, como la salud de los trabajadores, que exige el acometimiento de actuaciones muy diversas para evitar los accidentes y las enfermedades profesionales. Sin duda, entre el elenco de actuaciones adoptables al respecto, la regulación jurídica ocupa un papel axial. Su tratamiento parte de la consideración de la salud como bien jurídico protegido, vertebrándose desde esa premisa un conjunto de disposiciones normativas y de actuaciones institucionales para garantizar ese derecho. En nuestra experiencia concreta, se ha experimentado un considerable desarrollo normativo de estos temas, modernizando nuestro ordenamiento y amoldándolo a las directrices imperantes en los países del entorno

1 Profesor Titular de Derecho del Trabajo. Universidad de Córdoba. 
comunitario. Pero la principal paradoja son los escasos resultados alcanzados pese al notable esfuerzo de modernización normativa, considerando la evolución del número de accidentes y su incidencia general en la población trabajadora.

Nuestro país es un ejemplo hasta cierto punto paradigmático, pues el incremento de las medidas preventivas y el refuerzo de las garantías jurídicas no se ha visto acompañado de correlativas disminuciones en las tasas de accidentes. Todo lo contrario, la siniestralidad muestra una radiografía evolutiva en progresión continua. Acotando, por ejemplo, un arco temporal de cinco años, con la referencia de la Ley 31/1995, de 8 de noviembre, de Prevención de Riesgos Laborales (en adelante LPRL), se observa una línea de tendencia ascendente en la evolución general de los accidentes profesionales, tanto los acontecidos durante la jornada como los realizados "in itinere", con porcentajes comprendidos entre el 7 y el $20 \%$ de variación interanual ${ }^{2}$, tal y como se observa en el gráfico 1.

\section{GRÁFICO 1 \\ Evolución de los accidentes de trabajo totales en España en el periodo 1985-2000}

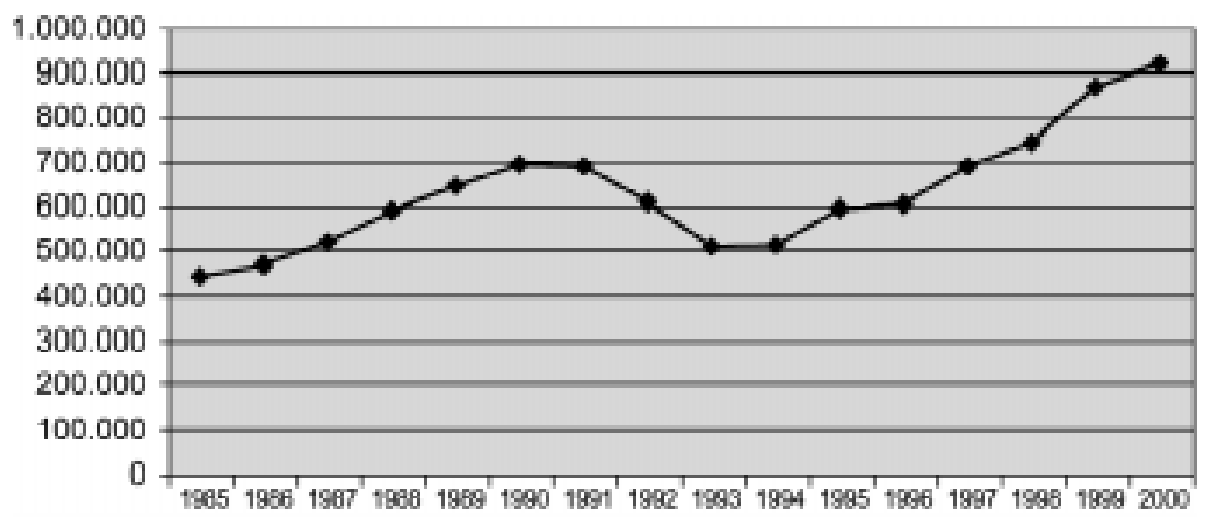

Fuente: Anuario de Estadísticas Laborales y Asuntos Sociales, Ministerio de Trabajo y Asuntos Sociales. Fuente 2000: Resúmenes Estadísticos de Siniestralidad Laboral, Miniserio de trabajo y Asuntos Sociales.

2 Sobre estos datos, vid. Economía, trabajo y sociedad. Memoria sobre la situación socioeconómica y laboral, CES, Madrid, años 1995 a 1999 (pp. 333, 369, 441, 383 y 411, respectivamente). 
Huelga enfatizar los costos anejos a estos datos, no sólo en pérdidas humanas con cifras que superan el millar de muertos al año duplicando la media comunitaria, sino en términos económicos ponderando los gastos que ello genera al sistema en su conjunto (cuotas de accidentes, jornadas perdidas, etc) ${ }^{3}$.

No deja de ser paradójica la introducción en nuestro ordenamiento de nuevas vías flexibilizadoras y desreguladoras, tal como ha acontecido tras las últimas reformas laborales, y que dicha equiparación a los sistemas jurídicos de nuestro entorno se quiebre de lleno en los resultados de la salud laboral y la política preventiva ${ }^{4}$. Mientras el Derecho del Trabajo no deja de teñirse de un sesgo "economicista" que "empresarializa" cada vez más sus contenidos bajo el paraguas de la flexibilidad, esa inercia no cesa de erosionar el carácter protector de dicha disciplina, no sólo en general con crasos retrocesos en la plataforma de derechos laborales, sino específicamente en temas tan significativos como la salud de la población trabajadora. Por tanto, el hecho que la implantación del modelo de prevención de riesgos coincida con la elevación de las tasas de accidentes genera un distanciamiento entre la bondad de la norma y la efectividad de sus previsiones, con ironías, rayana la filosofía del derecho, entre la validez y eficacia de las disposiciones jurídicas.

\section{Un breve apunte sobre el marco jurídico de la prevención de riesgos laborales}

El marco jurídico de la prevención está compuesto por un conjunto de normas y medidas adoptadas o previstas en todas las fases de la empresa dirigidas a evitar o disminuir los riesgos profesionales, proteger la seguridad y la salud en el trabajo, y minorar los factores de riesgo y accidente; to do ello, mediante la utilización de los derechos de información, consulta, participación equilibrada y formación de los trabajadores y sus representantes

3 Con estimaciones próximas al 3\% del PIB, según la Memoria del CES, supra cit, 1999, p. 421.

4 Sobre ambos aspectos, me remito a nuestros trabajos "Consecuencias de la flexibilidad y la desregulación en la configuración del mercado de trabajo y en la ordenación de las relaciones laborales", en la obra col. Tecnología y sociedad en el nuevo siglo (Coord. Félix Tezanos/Sánchez Morales), Ed. Sistema, Madrid, 1998, pp. 268 y ss; o "Principios y caracterización general de la Ley 31/1995 de Prevención de Riesgos Laborales", en la obra col. La Ley de Prevención de Riesgos Laborales (Coord. Escudero Rodríguez, R), Consejo Andaluz de Relaciones Laborales, Sevilla, 1997, pp. 79 y ss. 
legales ${ }^{5}$. Nos encontramos, por tanto, ante una materia con numerosas aristas y ramificaciones. La actividad preventiva es consustancialmente poliédrica, no sólo por incidir sobre un bien jurídico como la salud, sino porque, lejos de su consideración desde un prisma punitivo-represivo, cobra más relevancia la política de prevención. Dicho en otros términos, nos situamos en el terreno de los comportamientos socialmente deseados bajo una conciencia de seguridad forjable en niveles muy diversos y que precisamente no es patente exclusiva de las relaciones laborales. Un prisma, en definitiva, más institucional, social o cultural que estrictamente regulador 0 reglamentista.

Lo expuesto supone un factor que mitiga de al gún modo la responsabilidad atribuible a la regulación jurídica. Estaúltima está formada por disposiciones de muy diverso rango y orientación, y que además ha experimentado sustanciales modificaciones en muy breve tiempo. De una normativa desfasada, como la Ordenanza General de Seguridad e Higiene de 1971, la Ley de Prevención de 1995 logró conferir una visión unitaria amoldando nuestra legislación a las orientaciones internacionales, especialmente con las decisiones de la Unión Europea y con los compromisos contraídos con la Organización Internacional del Trabajo. Ahora bien, tampoco es menos cierto que de una regulación insuficiente hemos pasado a una "profusión relegalizadora" que también genera serios problemas de cohonestación normativa e implantación institucional de sus contenidos.

Son muy numerosas las fuentes que canalizan la política preventiva, las cuales descansan en cuatro niveles básicos de regulación. El primero lo componen las fuentes supranacionales, existiendo un extensísimo caudal de Directivas comunitarias que abordan aspectos de la salud y seguridad en el trabajo ${ }^{6}$. El segundo nivel está personificado en la Ley de Prevención de 1995, amén de otros textos con igual rango legal (p.ej. Estatuto de los Trabajadores, o Ley de Infracciones y Sanciones del orden social). El tercer nivel tiene un rango reglamentario, previéndose un profuso desarrollo de disposiciones administrativas para concretar sus previsiones e incorporar el contenido de

5 Sobre ese esbozo genérico de la materia preventiva, vid. Directiva 89/391 CEE, directiva marco de la Unión Europea en esta materia.

6 Sobre dicho proceso de armonización, junto con un análisis comparado del mismo en los diferentes países de la Unión Europea, vid. Sempere Navarro, A.V. y Cardenal Carro, M., Transposición de la Directiva Marco de Seguridad Laboral en diferentes países de Europa, Universidad de Murcia/ Fundación Mapfre, Madrid, 2000. 
ciertas Directivas. Mientras que el cuarto nivel reside en los convenios colectivos, especialmente en lo que atañe a la organización institucional de la prevención.

Así pues, uno de los problemas con que tropieza la aplicación de las normas de seguridad y salud estriba en la dispersión reguladora de que adolece dicho régimen jurídico. Bien es verdad que se trata de un problema en cierto mo do inmanente a la naturaleza y las fuentes que convergen en esta materia. Sin embargo, a la laberíntica trasposición de Directivas comunitarias, se une un extenso número de reglamentos pendientes de desarrollar, lo cual dificulta ese proceso de vertebración normativa y, a la postre, articulación institucional del modelo preventivo.

\section{Algunos puntos críticos del modelo preventivo}

A la luz de lo expuesto, subsisten una serie de "puntos críticos" en el modelo diseñado en las normas de prevención. Algunos análisis relacionan el incremento de la siniestralidad con el crecimiento sostenido de la actividad económica. Ese crecimiento intensifica el funcionamiento de las empresas, con prolongaciones de las jornadas, aumento de los ritmos de trabajo, establecimiento de nuevos horarios y de fórmulas de descanso equivalente. De igual manera, el suave incremento de las tasas de ocupación y de empleo generado tras las últimas reformas laborales conlleva un aumento de los trabajadores expuestos a riesgos profesionales. Consiguientemente, el mantenimiento de la siniestralidad sería un efecto implícito a la ampliación subjetivo-material de la actividad productiva ${ }^{7}$.

Sin restar validez a esta línea argumental, no logra explicar empero por sí misma el estado actual de la seguridad y salud en el trabajo. Aunque la situación de anquilosamiento que empaña esta materia responde a "patologías" muy diversas, gran parte de ello tienen un basamento de orden institucional. Podemos argumentar que la complejidad que rodea el armazón jurídico de la seguridad e higiene, tanto como la propia "filosofía preventiva", requiere plazos dilatados para la asunción efectiva de sus contenidos. Así ha ocurrido con la puesta en funcionamiento de órganos como la Comisión Nacional de Seguridad y Salud, con la Fundación para la prevención de

7 Esta línea argumental ya era mantenida hace unos años por el CES (Memoria..., año 1997, p. 441), y sigue manteniénd ose al hilo del incremento de factores asociados a la carga de trabajo (Memoria..., año 1999, pp. 415 a 417). 
riesgos, o con el lento proceso de acreditación de entidades para actuar como servicios externos de prevención; y así sigue aconteciendo con el desarrollo normativo todavía pendiente. Sin embargo, subsisten disfuncionalidades muy notables en la organización empresarial de la prevención.

En primer término, debemos retener los diversos órganos que vertebran la actividad preventiva, ora institucionales, ora especializados, ora participativos, estructurados según la dimensión de las empresas, y considerar asimismo el cuadro de competencias normativamente atribuidas ${ }^{8}$. Dicho marco prefigura "instituciones-base", como los servicios de prevención o los delegados de prevención, cauces instrumentales, como los derechos de información o la propia actividad formativa impartida por las empresas, o "instituciones-guía" para el seguimiento y vigilancia, ya internamente mediante comisiones paritarias o externamente a través de la inspección de trabajo. Por consiguiente, terminar de vertebrar ese cuadro institucional y conferirle una fluidez interna es una línea de trabajo de inmediato acometimiento. Máxime si consideramos el porcentaje de centros que tienen el número mínimo de delegados de prevención (sólo un 56\%), centros que tienen un número menor de delegados que el exigido legalmente (14.5\%), y, sobretodo, centros que ni si quiera disponen de tales representantes $(26 \%)^{9}$. Lo que confirma los defectos institucionales de la organización preventiva.

\section{Medidas para una institucionalización más adecuada del modelo pre- ventivo}

El mantenimiento de la siniestralidad laboral en nuestro país configura una relación inversamente proporcional entre el proceso juridificador acometido y los resultados finalmente cosechados. Esto, además de evidenciar la separación entre los aspectos jurídicos y metajurídicos anejos a esta materia, también pone de relieve que dichas políticas, al igual que la salud laboral, deben afrontarse como un problema integral. Desde ese prisma, son varias las medidas acometibles para lograr una mayor institucionalización del modelo preventivo, aunque sintéticamente podemos diseñar cuatro niveles posibles de actuación.

8 Vid cuadro sobre la vertebración orgánico-competencial de la materia preventiva que aparece como anexo.

9 CES, Memoria..., cit, 1999, p. 420. 
1) El primer nivel tiene un alcance estructural. La siniestralidad tiene una relación directa con la externalización en el empleo (ETT, contratas, etc.), con la propia ordenación del tiempo de trabajo (p.ej. régimen de descansos) y, como se observa en el gráfico 2 , con la contratación temporal.

\section{GRÁFICO 2}

\section{Evolución de las tasas de incidencia por mil trabajadores según tipo de contrato 1990-1999}

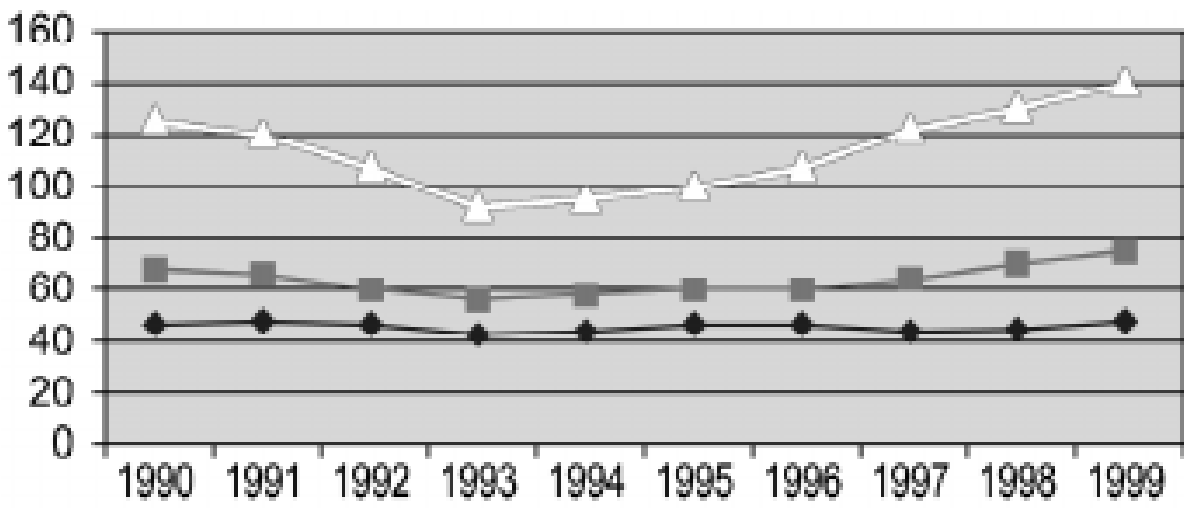

\section{$\multimap$ Fijos - -Temporales $=$ Total nacional}

Fuente: Anuarios de Estadísticas Laborales y Asuntos Sociales, Ministerio de Trabajo y Asuntos Sociales.

Bien es verdad que las últimas reformas laborales no han dejado de establecer medidas para la conversión de contratos temporales en indefinidos, aunque los resultados no han sido demasiado satisfactorios al hilo del empleo estable finalmente generado. También la última reforma ha modificado precisamente el régimen jurídico del trabajo en contratas o subcontratas potenciando los derechos de información e introduciendo medidas complementarias de control sindical ${ }^{10}$. Pero aun así, se debería profundizar en las

10 Nuevos párrafos 3 y 4 del art. 42, en su nueva redacción a raíz del RDL 5/2001, de 2 de marzo de 2001, de medidas urgentes de reforma del mercado de trabajo para el incremento del empleo y la mejora de su calidad. 
prácticas de externalización, por ejemplo mediante la aplicación de los deberes de coordinación existentes entre la ETT y la empresa usuaria a las relaciones entre contratas y subcontratas.

2) Un segundo bloque de actuaciones estriba en la divulgación, vigilancia y control de la prevención, siendo ello uno de los ámbitos más relevantes de las políticas de seguridad y salud. Su eficacia no depende únicamente de una vertebración racional de los aspectos orgánico-normativos, sino de la divulgación previa de sus contenidos y de su posterior seguimiento. De hecho, un gran número de siniestros son producidos por el desconocimiento de los riesgos inherentes al propio trabajo. Sólo así es posible enraizar la "cultura preventiva" auto-erigida en principio rector de esta materia ${ }^{11}$. A tal efecto, varios son los planos de incidencia, desde las campañas divulgativas en los medios de comunicación, la formación de empresarios y trabajadores, hasta la realización de estudios que analicen la siniestralidad en sectores y actividades proclives a ella (construcción, minería, transporte terrestre etc.) ${ }^{12}$.

3) El tercer bloque tiene una vertiente orgánico-institucional. Se trata de asentar el modelo organizativo de prevención diseñado en los textos legales, el cual se despliega sobre una tupida red de órganos, instituciones y administraciones. La LPRL implica a diversos departamentos ministeriales, mutuas, inspección de trabajo, y mecanismos varios de prevención a través de la negociación colectiva. Centrándonos, por ejemplo, en los dos últimos vectores apuntados, cabe pensar en una redefinición del papel de la inspección en el control de la seguridad en el trabajo. Aparte de la dotación de medios materiales y, sobremanera, personales, no se trata sólo de que ejerzan su rol represivo-punitivo, al amparo, eso sí, de un endurecimiento del régimen de responsabilidades y sanciones, sino de que desarrollen un papel no menos relevante de divulgación de las directrices normativas, de colaboración y asesoramiento a los agentes sociales cuando son aplicadas en la práctica. Otro fleco es la integración por los convenios colectivos de la estructura preventiva diseñada en la LPRL. Existen, en efecto, un elevado número de

11 Exposición de Motivos de la LPRL (punto 4/2).

12 Memoria del CES, cit, 1999, p. 407. 
empresas que no han constituido los comités de seguridad y de centros sin delegados de prevención. Por consiguiente, subsiste esa labor inacabada de articulación del cuadro orgánico preventivo a raíz de los diversos niveles en que se vertebra (órganos institucionales, especializados y de participación) y de las competencias atribuidas según la dimensión de la empresa.

4) Por último, desde el terreno jurídico se plantean dos cuestiones finales. La primera estriba en racionalizar la regulación de la normativa sobre seguridad y salud laboral. Sin ir más lejos, el proceso de trasposición de las Directivas comunitarias se está llevando a cabo transcribiendo prácticamente su contenido. Por tanto, impera una labor de unificación y simplificación de dicha normativa para facilitar su conocimiento, además de considerar las particularidades de la materia y de la organización preventiva en nuestro sistema de relaciones laborales. Asimismo, y como actuación algo más específica, una plausible propuesta incide en la incentivación económico fiscal de la prevención, favoreciendo a las empresas con menos bajas y penalizando las que alcancen mayores tasas de siniestralidad ${ }^{13}$.

13 Se trata de una propuesta que ya era contemplada en la Disposición Adicional 1ạ de la Ley 65/ 1997, de 30 de diciembre, de Presupuestos Generales del Estado, y que vuelve a actualizarse en recientes estudios, como por ejemplo el denominado "Informe Durán" sobresiniestralidad laboral; dicho estudio (no publicado en el momento de elaborar el presente trabajo) propone además atribuir al empresario el pago de la prestación económica por incapacidad temporal durante el período inicial de la baja, con una reducción equivalente de las cotizaciones por riesgos profesionales. 
ANEXO

Cuadro orgánico y competencial en materia de salud laboral

\begin{tabular}{|c|c|c|c|c|}
\hline MATERIAS & $\begin{array}{l}\text { ÓRGANOS } \\
\text { INSTITUCIONALES }\end{array}$ & $\begin{array}{l}\text { ÓRGANOS } \\
\text { ESPECIALIZADOS }\end{array}$ & $\begin{array}{l}\text { ÓRGANOS DE } \\
\text { PARTICIPACION }\end{array}$ & $\begin{array}{l}\text { SERVICIOS DE } \\
\text { PREVENCIÓN }\end{array}$ \\
\hline $\begin{array}{l}\text { Evaluación de riesgos y planificación de } \\
\text { la acción preventiva }\end{array}$ & $\begin{array}{l}\text { Información } \\
\text { documental }\end{array}$ & $\begin{array}{l}\text { Información } \\
\text { documental }\end{array}$ & Participación & $\begin{array}{l}\text { Información } \\
\text { documental }\end{array}$ \\
\hline $\begin{array}{l}\text { Estadísticas sobre AT y EP y sus conse- } \\
\text { cuencias, índices de siniestralidad y es- } \\
\text { tudios del medio ambiente laboral }\end{array}$ & Información & & & \\
\hline $\begin{array}{l}\text { Relación de AT y EP que originen una inva- } \\
\text { lidez laboral superior a un día de trabajo }\end{array}$ & $\begin{array}{l}\text { Información } \\
\text { documental }\end{array}$ & $\begin{array}{l}\text { Información } \\
\text { documental }\end{array}$ & & $\begin{array}{l}\text { Información } \\
\text { documental }\end{array}$ \\
\hline $\begin{array}{l}\text { Relación de puestos de trabajo exentos } \\
\text { de riesgos para la mujer embarazada }\end{array}$ & Consulta & & & \\
\hline $\begin{array}{l}\text { Riesgos para la seguridad y salud de los } \\
\text { trabajadores en general y particularmen- } \\
\text { te para cada puesto de trabajo }\end{array}$ & Información & Información & & Información \\
\hline $\begin{array}{l}\text { Medidas y actividades de protección y } \\
\text { prevención aplicables }\end{array}$ & $\begin{array}{l}\text { Información y } \\
\text { consulta }\end{array}$ & $\begin{array}{l}\text { Información y } \\
\text { propuesta }\end{array}$ & & Información \\
\hline Medidas de emergencia & Información & Información & & Información \\
\hline $\begin{array}{l}\text { Designación de trabajadores encarga- } \\
\text { dos de las medidas de emergencia }\end{array}$ & Consulta & Consulta & & \\
\hline Paralización de actividades & Decisión & $\begin{array}{l}\text { Propuesta de } \\
\text { adopción y } \\
\text { decisión, en su } \\
\text { defecto }\end{array}$ & & $\begin{array}{l}\text { Información } \\
\text { documental }\end{array}$ \\
\hline Práctica de reconocimientos médicos & $\begin{array}{l}\text { Información } \\
\text { documental }\end{array}$ & $\begin{array}{l}\text { Información } \\
\text { documental }\end{array}$ & & \\
\hline Reconocimientos médicos obligatorios & Consulta & & & \\
\hline $\begin{array}{l}\text { Conclusiones de los reconocimientos } \\
\text { médicos }\end{array}$ & $\begin{array}{l}\text { Información } \\
\text { documental }\end{array}$ & $\begin{array}{l}\text { Información } \\
\text { documental }\end{array}$ & $\begin{array}{l}\text { Información } \\
\text { documental }\end{array}$ & $\begin{array}{l}\text { Información } \\
\text { documental }\end{array}$ \\
\hline $\begin{array}{l}\text { Planificación y organización del trabajo } \\
\text { e introducción de nuevas tecnologías } \\
\text { (en materia de seguridad) }\end{array}$ & Consulta & Consulta & Debate previo & \\
\hline $\begin{array}{l}\text { Daños producidos en la salud e } \\
\text { integridad de los trabajadores }\end{array}$ & Información & Información & Información & \\
\hline $\begin{array}{l}\text { Actividades y servicios de prevención y } \\
\text { desarrollo; designación detrabajadores; } \\
\text { recurso a servicios externos }\end{array}$ & Consulta & Consulta & Debate previo & \\
\hline $\begin{array}{l}\text { Memoria y programación anual de los } \\
\text { servicios de prevención }\end{array}$ & & & $\begin{array}{l}\text { Información y } \\
\text { consulta }\end{array}$ & \\
\hline $\begin{array}{l}\text { Documentación einformación proceden- } \\
\text { tes de sujetos u órganos encargados de } \\
\text { servicios de protección y prevención }\end{array}$ & & Información & Información & \\
\hline $\begin{array}{l}\text { Cumplimiento de la normativa de pre- } \\
\text { vención de riesgos }\end{array}$ & Vigilancia & $\begin{array}{l}\text { Vigilancia y } \\
\text { control }\end{array}$ & & \\
\hline $\begin{array}{l}\text { Resultado de controles periódicos de } \\
\text { las condiciones de trabajo y de la activi- } \\
\text { dad laboral de los trabajadores }\end{array}$ & $\begin{array}{l}\text { Información } \\
\text { documental }\end{array}$ & $\begin{array}{l}\text { Información } \\
\text { documental }\end{array}$ & $\begin{array}{l}\text { Información } \\
\text { documental }\end{array}$ & $\begin{array}{l}\text { Información } \\
\text { documental }\end{array}$ \\
\hline
\end{tabular}

Fuente: Garrido Pérez, E. "Las participaciones de los trabajadores en materia de prevención de riesgos laborales en la Ley 31/ 1995", Relaciones Laborales, no 20 y elaboración propia. 